\title{
Erratum to: Hip and groin pain in adolescents
}

Tal Laor

Published online: 12 May 2010

(C) Springer-Verlag 2010

\section{Erratum to: Pediatr Radiol}

\section{DOI 10.1007/s00247-009-1517-x}

In the 4th paragraph on page 465 , the sentence that begins "As a general rule..." should read as follows:

As a general rule, an optimally positioned frontal radiograph (without excessive pelvic tilt, which can affect the accuracy of determining acetabular retroversion) shows a distance between the pubic symphysis and the coccyx of approximately $3.2 \mathrm{~cm}$ in males and $4.7 \mathrm{~cm}$ in females [40].

The online version of the original article can be found at http://dx.doi. org/10.1007/s00247-009-1517-x.

T. Laor $(\bowtie)$

Department of Radiology, Cincinnati Children's Hospital Medical

Center and University of Cincinnati College of Medicine,

Cincinnati, OH 45229, USA

e-mail: laor@cchmc.org 